\title{
Performance Characteristics of Cemented Tailings Containing Crumb Rubber as a Filling Material
}

\author{
Zhuoqun Yu $(\mathbb{D}$, Nan Qin $(\mathbb{D}$, Sa Huang, Jianguang Li $(\mathbb{D}$, and Yongyan Wang \\ School of Mechanical and Electrical Engineering, Qingdao University of Science and Technology, Qingdao 266061, China \\ Correspondence should be addressed to Nan Qin; qinnan_qust@126.com
}

Received 29 October 2021; Accepted 10 January 2022; Published 25 January 2022

Academic Editor: Abílio De Jesus

Copyright (C) 2022 Zhuoqun Yu et al. This is an open access article distributed under the Creative Commons Attribution License, which permits unrestricted use, distribution, and reproduction in any medium, provided the original work is properly cited.

\begin{abstract}
Increasing amounts of tailings and waste rubber tires have caused threats to the environment. In order to reuse these solid wastes, this study proposed a cemented tailings material containing crumb rubber recovered from waste tires. Unconfined compression tests and thermal conductivity measurements were conducted to evaluate the feasibility and performance of the proposed cemented tailings. Results revealed that the stress-strain behavior of the cemented tailings changed by the inclusion of crumb rubber. The unconfined compressive strength of cemented tailings decreased with increasing crumb rubber content. The inclusion of crumb rubber increased the failure strain and nonlinearity index of the cemented tailings. It was found that the addition of $4 \%$ crumb rubber provided the greatest improvement in ductility. The increase of the rubber content further increased the thermal insulation capacity of the cemented tailings. The low stiffness and the dimpled surface of the crumb rubber were responsible for the reduced compressive strength and thermal conductivity of the cemented tailings. In conclusion, the crumb rubber had both positive and negative effects on the cemented tailings. In practical application, the rubber admixture amount should be flexibly adjusted for different use case to make the cemented tailings material show the most suitable performance characteristic.
\end{abstract}

\section{Introduction}

The huge demand for mineral resources has stimulated a significant increase in mining volumes. Meanwhile, large quantities of mine tailings were produced with the mining and processing of ore. It was estimated that there were 25 billion tonnes of solid wastes in the mines of China, and this number is continuously increasing year by year [1]. The improper disposal of the tailings may cause dangerous environmental problems; more than 70 million Yuan was spent every year on tailings disposal and risk monitoring in China [2]. Most tailings were disposed of in tailings reservoirs, which was a source of man-made hazards [3]. Waste rubber tires constitute one major part of solid waste in a modern society. The total weights of waste rubber tires generated in the United States and China were more than 100 million tonnes [4]. The huge amounts of waste tires may cause hazardous environmental problems such as fire hazards and use of surface land resources [5]. Recently, China still had 5.2 million tonnes of waste tires stacked in open-air sites every year [6]. Therefore, the disposal of waste tires has become a major challenge nowadays. It is necessary to pave new ways for the tailings and waste tires disposal.

The joint reuse of these solid wastes as aggregates of cement-based materials may be an environmentally friendly solution. Typical cement-based materials are mixtures of aggregates, binder, and water. And they have been widely utilized in various situations. However, huge demands of aggregates for the cement-based materials have led to the shortage of natural river sand [7]. In order to alleviate the resource shortage, some researchers have shown that iron tailings can be utilized for an alternative to natural sand in concrete. Zhao et al. [8] reported that a $40 \%$ replacement of natural aggregate by the tailings had a limited effect on the workability and mechanical properties of the ultra-high performance concrete. Liu et al. [9] found that a $20 \%$ replacement of natural river sand by iron tailings in sprayed concrete achieved the best performance. These studies have reflected the great value of tailings as the aggregate of cement-based materials. 
However, there were few studies on the use of tailings as the sole aggregate for cementitious materials. There were only some studies that showed that the tailings were suitable to be used as the sole aggregate of cemented tailings backfill materials for backfilling the mining stope and improving the ground stability and safety $[10,11]$. A typical cemented tailings backfill is a cement-based material consisting of cement, tailings, and water. The cement content of the typical cemented tailings backfill was relatively low. To ensure a high mechanical strength and a good workability for backfilling operations, the solid content of the cemented tailings backfill materials is between $70 \%$ and $85 \%[12,13]$. For the past few years, researchers have put great efforts to improve or modify the ordinary cemented tailings backfill material by adding additives [14-16]. For example, Guo et al. [17] found that the sodium silicate gel could accelerate the binder hydration process in cemented tailings and then increase the strength of cemented tailings. Chen et al. [18] conducted unconfined compressive strength tests on cemented tailings containing polypropylene fiber and the results indicated that the fiber can improve the ductility and stiffness of cemented tailings. Festugato et al. [19] added polypropylene fibers into cemented tailings to improve the shear resistance. In addition, Koohestani et al. [20] investigated the influence of maple-wood sawdust on the compressive performance of cemented tailings. It was reported that the addition of $12.5 \%$ maplewood sawdust could improve the strength of cemented tailings.

Previous researchers have also investigated the feasibility of adding waste tire crumb rubber in the cementbased materials such as concrete and cement treated clay [21, 22]. For instance, Eldin and Senouci [23] examined the strength and toughness properties of concrete containing crumb rubber; they reported that the concrete containing rubber particles had lower strength and more ductile behavior than the ordinary concrete. Atahan and Yvcel [24] found that the incorporation of crumb rubber in concrete decreased the compressive strength and increased the impact resistance. They suggested that the flexible concrete with rubber aggregate could be used as highway barriers. However, there have been few researchers in the past who carried out the feasibility study on cemented tailings containing crumb rubber.

In this paper, cemented tailings containing waste tire crumb rubber were proposed to pave new ways for the tailings and waste tires disposal. Compared to the low strength cemented tailings backfill used solely for underground voids filling, the investigated cement contents of cemented tailings material were set relatively higher in this study to study the feasibility as a more widely used filling material. A series of cemented tailings samples containing various contents of crumb rubber were prepared. Scanning electron microscopy (SEM) analysis was used to investigate the morphological properties of the crumb rubber. Unconfined compression tests and thermal conductivity measurements were conducted on cemented tailings samples. The performance of the cemented tailings was optimized by changing the content of crumb rubber.

\section{Materials and Methods}

2.1. Materials. The tailings for the sample preparation were taken from an iron mine in the central part of Shandong province, China. Its specific gravity was 2.45 . The mineralogical composition of the tailings was determined using X-ray diffraction (XRD; Bruker AXS D8 Advance Diffractometer), and the grain size distribution of the tailings was analyzed using a laser particle size analyzer (Mastersizer 3000, Malvern). Tests results are shown in Figure 1. It can be seen that the particle size distribution of the tailings is mainly concentrated in 200 to $1000 \mu \mathrm{m}$. The main substances of the tailings are quartz sand, ferric oxide, and calcium oxide. Main chemical properties of the tailings are shown in Table 1.

Crumb rubber obtained from the waste tires was used in this study. Its specific gravity was 1.09 . The iron wire and polymer fiber were reclaimed during the shredding process of waste tires. The main component of the crumb rubber was the waste tire rubber. Mechanical properties of waste tire rubber could be found in Table 1 . The average diameter of the rubber particle was about $2 \mathrm{~mm}$. The rubber content of cemented tailings samples in this study was determined to be $0 \%, 2 \%, 4 \%$, and $6 \%$ (by the weight of dry tailings). Besides, ordinary Portland cement P. O. 42.5 was used as the binder. In this study, the cement contents of cemented tailings samples were determined to be $10 \%$ and $25 \%$ by the dry weight of the tailings. City tap water was utilized as the mixing water for the sample preparation of cemented tailings samples.

2.2. Samples Preparation. The cylindrical samples with a diameter of $50 \mathrm{~mm}$ and a height of $100 \mathrm{~mm}$ were prepared for the unconfined compression tests. The mass concentration of cemented tailings was determined to be $75 \%$ according to the accumulated experience of previous studies and mine sites to fit the pumping requirements [18]. Tailings, crumb rubber, cement, and water with various proportions were mixed in a laboratory mixer for at least 10 minutes. After the mixing process, the cemented tailings slurry was cast into cylindrical moulds $(50 \mathrm{~mm}$ in diameter and $100 \mathrm{~mm}$ in height). The slump value of fresh cemented tailings slurry in this investigation was between $190 \mathrm{~mm}$ and $195 \mathrm{~mm}$, which is acceptable. After 12 hours of resting, the samples were demoulded and transferred into a humidity chamber to be cured at a temperature of $20^{\circ} \mathrm{C}$ and a relative humidity of $95 \%$ for 28 days. The curing condition was determined according to $[15,25]$. Cemented tailings samples in this study and their mix proportions are shown in Table 2, and three identical specimens were prepared for triplicate tests.

2.3. Unconfined Compression Tests. The unconfined compression tests for the cemented tailings samples were carried out to investigate the mechanical properties of the proposed material serving as underground backfill structures or above ground filling structures. According to the accumulated experience of cemented tailings backfill test methods [26, 27] 


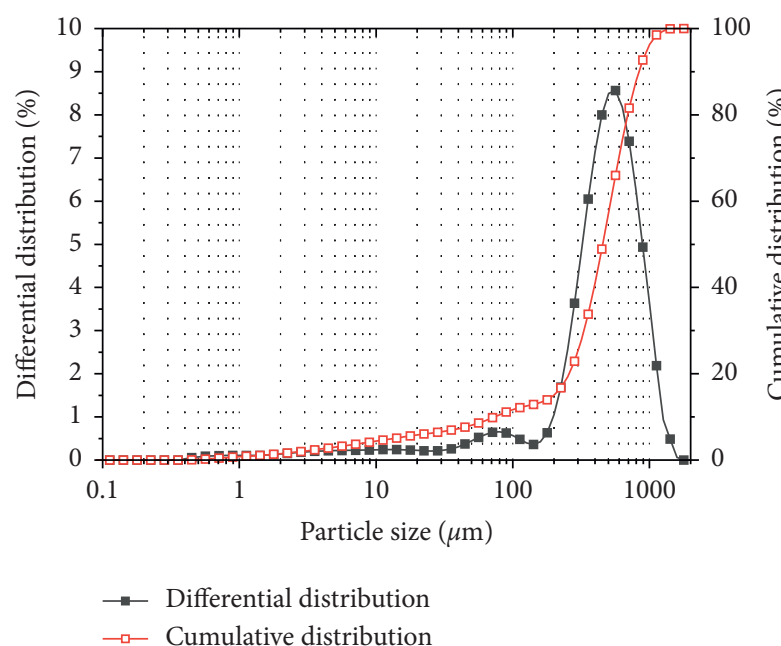

(a)

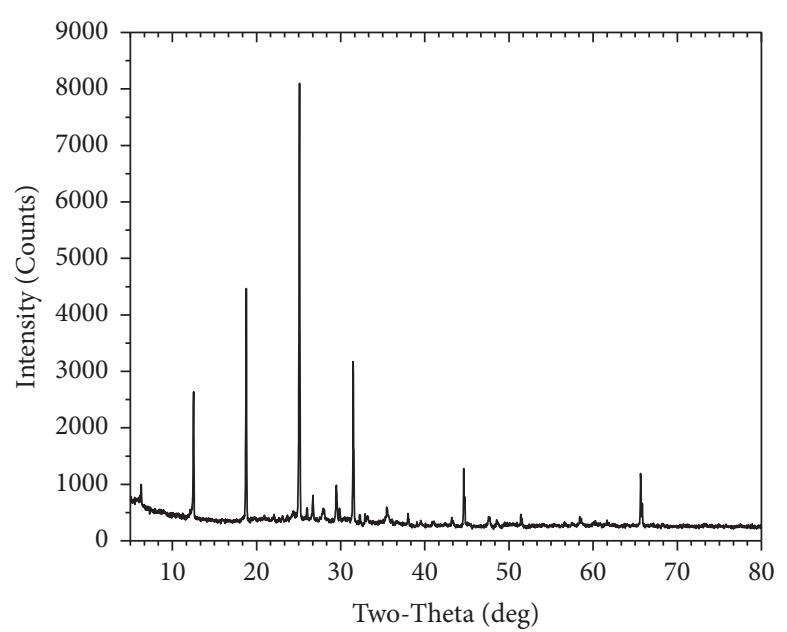

(b)

FIgure 1: Curves of (a) particle size distributions and (b) XRD of tailings.

TABle 1: Main chemical and physical properties of the rubber fiber and tailings.

\begin{tabular}{lcc}
\hline Chemical component (\%) & Waste tire rubber & Tailings \\
\hline Styrene butadiene rubber & 62.10 & - \\
Extender oil & 1.90 & - \\
Carbon black & 31.0 & - \\
Zinc oxide & 1.90 & - \\
Stearic acid & 1.20 & - \\
Sulfur & 1.10 & - \\
$\mathrm{MgO}_{\mathrm{Al}_{2} \mathrm{O}_{3}}$ & - & 12.93 \\
$\mathrm{SiO}_{2}$ & - & 8.89 \\
$\mathrm{CaO}$ & - & 27.41 \\
$\mathrm{Fe}_{2} \mathrm{O}_{3}$ & - & 18.68 \\
\hline
\end{tabular}

TABLE 2: Designation and mix proportions of cemented tailings samples used in this study.

\begin{tabular}{lcccccccc}
\hline Sample designation & C10 & C10R2 & C10R4 & C10R6 & C25 & C25R2 & C25R4 & C25R6 \\
\hline Cement content (\%) & 10 & 10 & 10 & 10 & 25 & 25 & 25 & 25 \\
Rubber content (\%) & 0 & 2 & 4 & 6 & 0 & 2 & 4 & 6 \\
Mass concentration (\%) & 75 & 75 & 75 & 75 & 75 & 75 & 75 \\
\hline
\end{tabular}

and the guideline of ASTM C39 [28] standard, the samples were tested immediately after reaching the curing aging. During the compression test, cemented tailings samples will be loaded at a constant displacement rate of $0.2 \mathrm{~mm} / \mathrm{min}$.

2.4. Measurement of Thermal Conductivity. The transient line heat source method was used to measure the thermal conductivity of cemented tailings samples. The basic theory of the line heat source method was based on a thermal conductivity model of a cylinder. The thermal conductivity can be calculated using the following equation:

$$
\lambda=P \cdot \frac{\ln \left(t_{2} / t_{1}\right)}{4 \pi L\left(\theta_{1}-\theta_{2}\right)},
$$

where $\lambda$ is the thermal conductivity of the material $(\mathrm{W} /(\mathrm{m} \cdot \mathrm{k}))$, $P$ is the heating power at a particular section of the heat line
(W), $t$ is the heating time of the corresponding temperature (s), $L$ is the length of the heat line $(\mathrm{m})$, and $\theta$ is the temperature of the heat line $\left({ }^{\circ} \mathrm{C}\right)$. The test device is a KD2 Pro thermal analyzer (Decagon Device, Inc.) with the TR-1 sensor. The test was carried out based on the guideline of ASTM D5334 [29].

\section{Results and Discussion}

3.1. SEM Analysis. SEM analysis for the crumb rubber was conducted as shown in Figure 2. It can be seen from Figure 2(a) that a crumb rubber particle is usually a tetrahedral structure. A long crack at the edge of the rubber particle can be observed from Figure 2(b), which may cause the reduction in strength and stiffness of the rubber particle. The lower stiffness and strength of the crumb rubber may cause the reduction in peak strength of cemented tailings. 


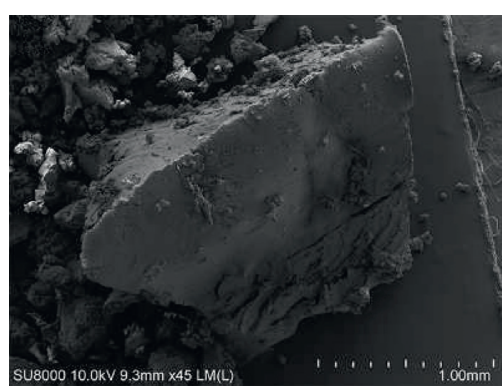

(a)

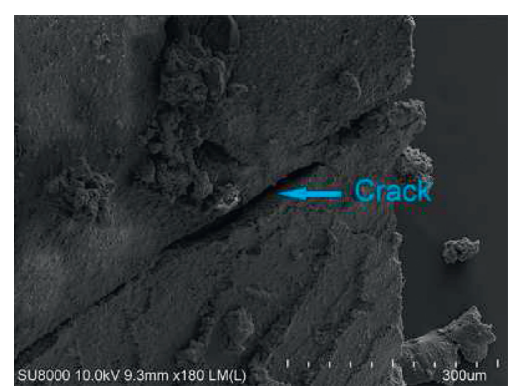

(b)

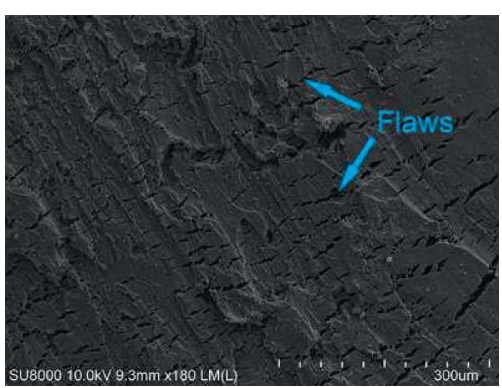

(c)

Figure 2: Typical SEM images of the crumb rubber: (a) overview with a $45 \mathrm{x}$ magnification; (b) long cracks with a $180 \mathrm{x}$ magnification; (c) surface flaws with a $180 \mathrm{x}$ magnification.

Cavities and microcracks can be observed on the surface of the rubber particle as shown in Figure 2(c). The dimpled surface may entrap air and create microvoids around the crumb rubber particles in the cemented tailings. This may cause the pronounced pore compaction stage in the stressstrain curves and the reduction in thermal conductivity. During the compression test, the stress will be concentrated on the voids in cemented tailings and produce many small cracks around the crumb rubber to alleviate the stress concentration in the cemented tailings. These effects will prevent the sudden failure of the cemented tailings caused by the stress concentration on the major cracks and improve their ductility. However, they will reduce the peak strength of cemented tailings due to the early development of small cracks. On the plastic stage during the compression test, the dimpled surface of crumb rubber (Figure 2(c)) may increase the friction between internal particles and improve the nonlinear behavior of the cemented tailings.

3.2. Stress-Strain Curves. Typical stress-strain curves of the cemented tailings samples are shown in Figure 3. It can be seen that there were pore compaction stage, elastic deformation stage, plastic deformation stage, and postpeak stage in a stress-strain curve. The pore compaction stage was more obvious for the higher rubber content cemented tailings samples. This indicated that the cemented tailings containing a higher rubber content had more pores in the structure. The physical properties of crumb rubber could be responsible for the formation of voids; reasons will be explained in the following sections. It can also be found that when the rubber content was constant, the pore compaction stage was more obvious and long for the lower cement content sample. This can be explained by the fact that more cement could produce more hydration products that could fill the pores [30-32]. The increase in rubber content caused a slight decrease in the elastic modulus of the cement-based tailing. Cemented tailings samples containing crumb rubber generally had a higher axial strain at peak stress (i.e., failure strain) and a lower unconfined compressive strength (UCS). It can also be seen that there were more obvious plastic stages on the cemented tailings samples containing $4 \%$ of crumb rubber. As shown in Figure 3, after the elastic deformation, a long plastic deformation occurred on C10R4 and C25R4. Cemented tailings samples containing crumb rubber had a larger failure strain and a lower UCS than ordinary cemented tailings samples. When the rubber content was constant, the sample with $25 \%$ cement content had a higher UCS and a smaller failure strain than the samples with $10 \%$ cement content. The inclusion of crumb rubber provided a limited relief from the sudden reduction in stress at the postpeak stage.

3.3. Unconfined Compressive Strength. The UCS values of cemented tailings samples are summarized in Figure 4. The compressive strength values of the samples C10, C10R2, C10R4, and C10R6 were $1.22 \mathrm{MPa}, 1.17 \mathrm{MPa}$, $1.13 \mathrm{MPa}$, and $0.93 \mathrm{MPa}$, respectively, while the compressive strength values of sample C25, C25R2, C25R4, and C25R6 were $5.38 \mathrm{MPa}, 5.20 \mathrm{MPa}, 4.01 \mathrm{MPa}$, and $3.79 \mathrm{MPa}$, respectively. It can be observed that the compressive strength of $10 \%$ cement content samples was lower than that of $25 \%$ cement content samples. This may have been due to the fact that the higher volume of cement can produce more hydration products and increase the strength of cement-based materials [31]. It can also be seen that, for both $25 \%$ cement content and $10 \%$ cement content samples, the compressive strength of cemented tailings containing crumb rubber was lower than that of cemented tailings without crumb rubber. For instance, the compressive strength of $10 \%$ cement content sample C10R6 was $0.93 \mathrm{MPa}$, which was $23.7 \%$ lower than that of dried sample C10. Similarly, the compressive strength of $25 \%$ cement content sample C25R6 was $3.79 \mathrm{MPa}$, which was $26.2 \%$ lower than that of undried sample C25.

Figure 5 depicts the variation in unconfined compressive strength for $10 \%$ cement content and $25 \%$ cement content cemented tailings samples with rubber content of $0 \%, 2 \%, 4 \%$, and $6 \%$. As shown in Figure 5(a) the UCS of the $10 \%$ cement content sample decreased as the rubber content increased. And a similar trend can be found in the $25 \%$ cement content samples as shown in Figure 5(b). A linear relationship between the compressive strength and rubber content can be observed and expressed as in equations (2) and (3): 


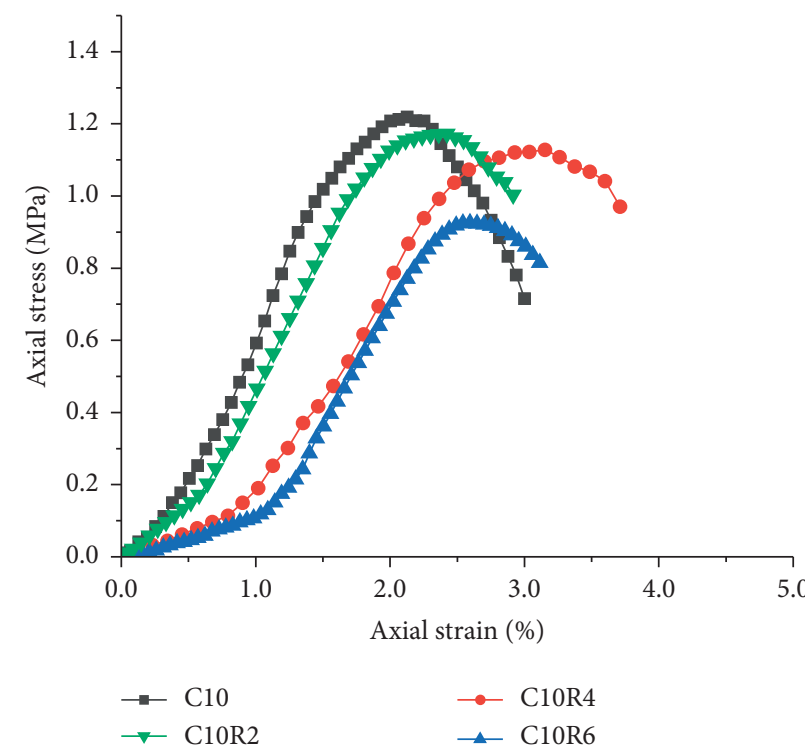

(a)

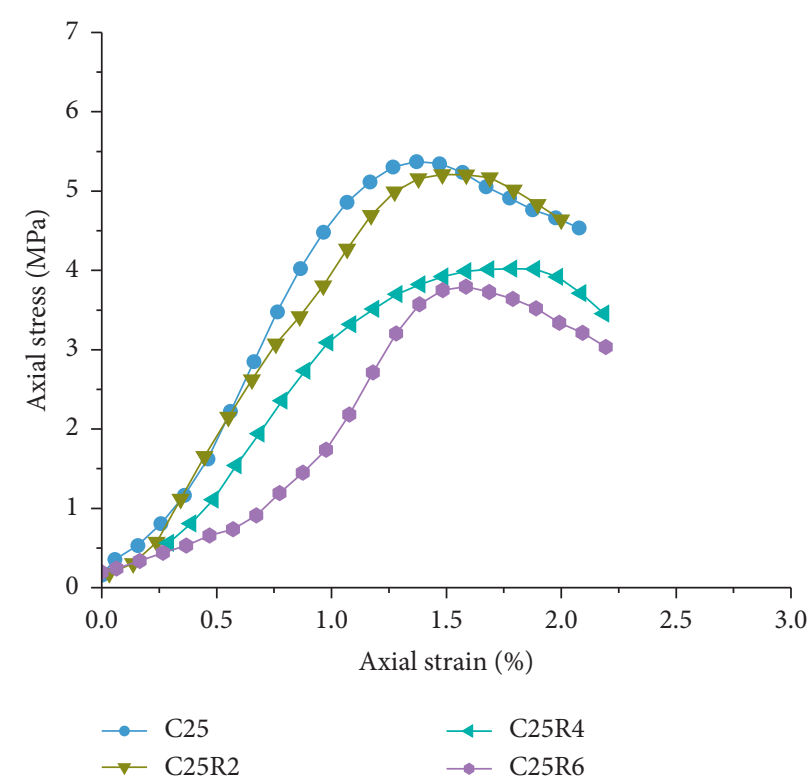

(b)

Figure 3: Typical stress-strain curves of (a) $10 \%$ and (b) $25 \%$ cement content cemented tailings samples.

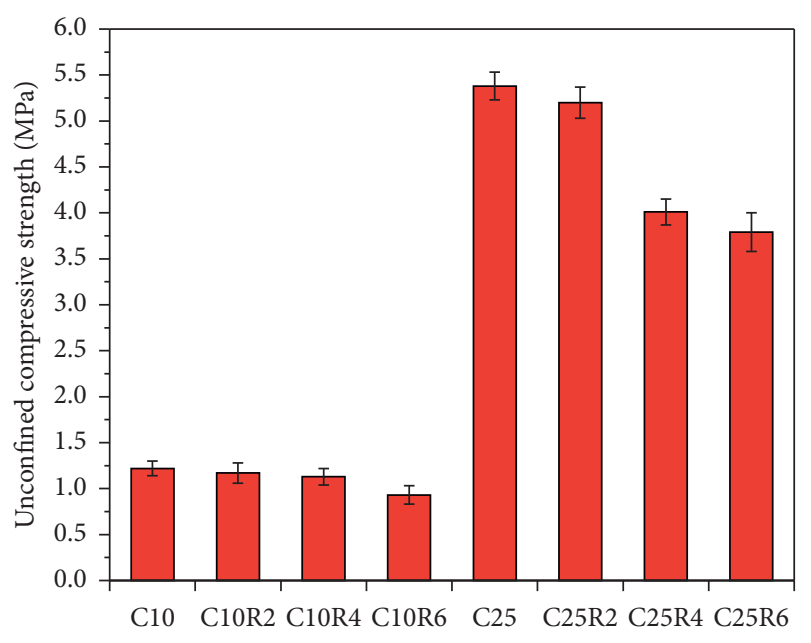

Samples designation

Figure 4: Unconfined compressive strength of cemented tailings samples.

$$
\begin{aligned}
S & =-0.046 C_{r}+1.249, \quad \text { for } 10 \% \text { cement content samples, } \\
R^{2} & =0.85
\end{aligned}
$$

$S=-0.298 C_{r}+5.489, \quad$ for $25 \%$ cement content samples, $R^{2}=0.90$,

where $S$ is the unconfined compressive strength (MPa); and $C_{\mathrm{r}}$ is the rubber content (\%). Comparing equations (2) and (3), it can be found that as the rubber content increased, the decrease in UCS of the $25 \%$ cement content sample was more pronounced than that of the $10 \%$ cement content sample. The decrease in UCS after the inclusion of crumb rubber may be due to the much lower stiffness of crumb rubber than the cemented tailings [23]. The difference in stiffness between the cemented tailings material and crumb rubber will increase when the cement content increases; this may have led to the more pronounced decrease in UCS of the higher cement content cemented tailings when crumb rubber was added. These results indicated that the continuous addition of crumb rubber could lead to a decrease in the UCS of cemented tailings. It was important to ensure that the cemented tailings with crumb rubber had an acceptable strength by controlling the crumb rubber content and increasing the cement content appropriately.

\subsection{Ductility of Crumb Rubber Modified Cemented Tailings.} Ductility is an important factor to guarantee the security of a material, which indicates the ability to sustain inelastic deformation to collapse without significant loss in resistance [33]. Several measures of the ductility of modified cementbased materials have been used in the past. One of the most common ductility indices is the ratio of different failure strains $[15,34]$. Based on this, a ductility index $D$ to evaluate the ductility of cemented tailings containing crumb rubber is proposed and defined as follows:

$$
D=\frac{\varepsilon_{r}}{\varepsilon_{o}}
$$

where $\varepsilon_{r}$ is the failure strain of cemented tailings containing crumb rubber, $\% ; \varepsilon_{o}$ is the failure strain of ordinary cemented tailings (without crumb rubber), \%. The failure strain values of cemented tailings samples are presented in Figure 6. And the calculation results of the ductility index $D$ for cemented tailings samples are presented in Figure 7. It 


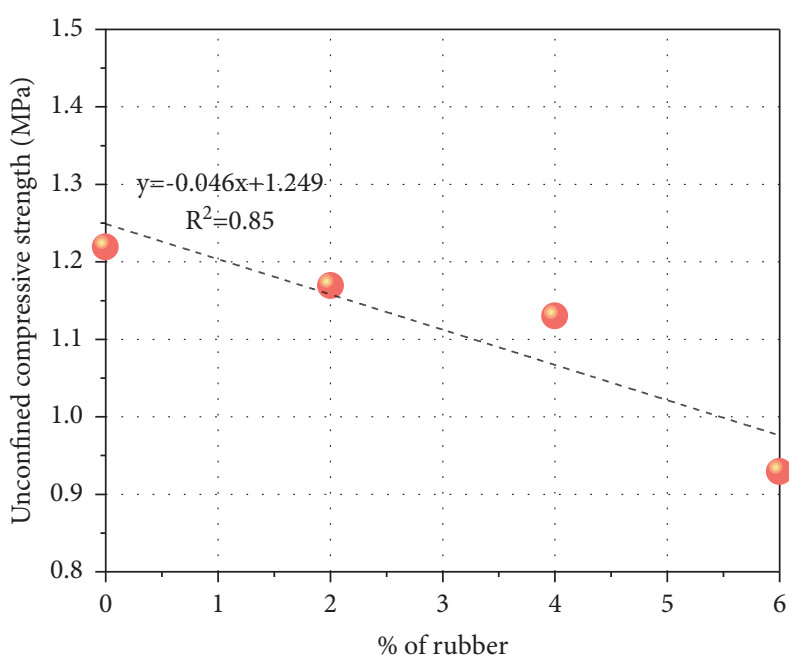

(a)

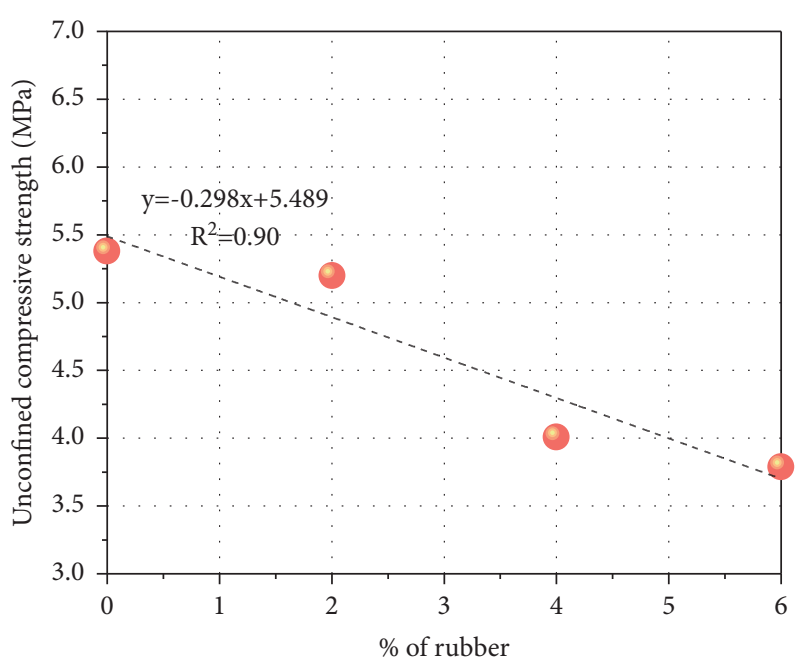

(b)

FIGURE 5: Relationship between the unconfined compressive strength and rubber content of cemented tailings: (a) 10\% cement content samples and (b) $25 \%$ cement content samples.

can be seen that, in the samples with $10 \%$ and $25 \%$ cement content, the ductility index increased and then decreased with the increasing of rubber content. The maximum ductility index was achieved when the rubber content was $4 \%$. This indicated that the extension of failure strain resulting from the addition of crumb rubber can be maximized when the crumb rubber content was $4 \%$. Although the

$$
\begin{aligned}
& D=1.21+0.24 \times \sin \frac{\pi\left(C_{r}-2\right)}{4}, \text { for } 10 \% \text { cement content samples, } \\
& R^{2}=0.94, \\
& D=1.15+0.18 \times \sin \frac{\pi\left(C_{r}-2\right)}{4}, \text { for } 25 \% \text { cement content samples, } \\
& R^{2}=0.90 .
\end{aligned}
$$

addition of $6 \%$ crumb rubber to the cemented tailings also improved the failure strain compared to the ordinary cemented tailings, the improvement effect was minimal. The relationship between the compressive strength and rubber content can be fitted and expressed using the sine function as equations (5) and (6):
Due to the flexibility of crumb rubber, the stress-strain behavior was more nonlinear for the cemented tailings with crumb rubber. The nonlinear behavior may also be amenable for the improvement in the ductility of cemented tailings. A nonlinearity index as shown in equation (7) was proposed and defined as the ratio of the deformation modulus and the elastic modulus based on the research on rubberized concrete [35]:

$$
N=\frac{\operatorname{tg} \beta}{\operatorname{tg} \alpha},
$$

where $\operatorname{tg} \beta$ is the elastic modulus of the material, and $\operatorname{tg} \alpha$ is the deformation modulus of the material. The nonlinearity indices are summarized in Figure 8. It can be seen that the nonlinear index of cemented tailings reached its maximum when the rubber content was $4 \%$. This echoes the increase of failure strain and ductility in the previous paragraph. A higher nonlinearity index indicated that the material could bear larger deformation with a considerable elastic modulus. Based on these results, the cemented tailings containing $4 \%$ of crumb rubber may be well suited for the use as a pressurebearing material under large deformations. For example, unstable overlying coal seams or rock layers were often encountered in underground mining [36]; the proposed material with high ductility had the feasibility to be used as a filling material for providing a good support and stability.

3.5. Thermal Conductivity. The thermal conductivity of each cemented tailings sample is shown in Figure 9. The thermal conductivity values of samples C10, C10R2, C10R4, and C10R6 were $0.292 \mathrm{~W} /(\mathrm{m} \cdot \mathrm{K}), 0.273 \mathrm{~W} /(\mathrm{m} \cdot \mathrm{K}), 0.251 \mathrm{~W} /(\mathrm{m} \cdot \mathrm{K})$, and $0.228 \mathrm{~W} /(\mathrm{m} \cdot \mathrm{K})$, respectively, while the thermal 


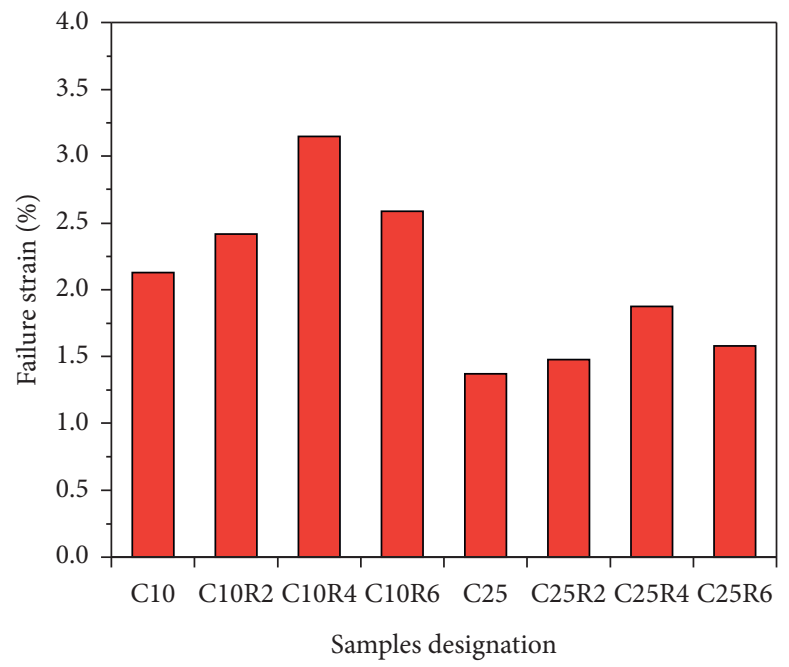

Figure 6: Failure strains of cemented tailings samples.

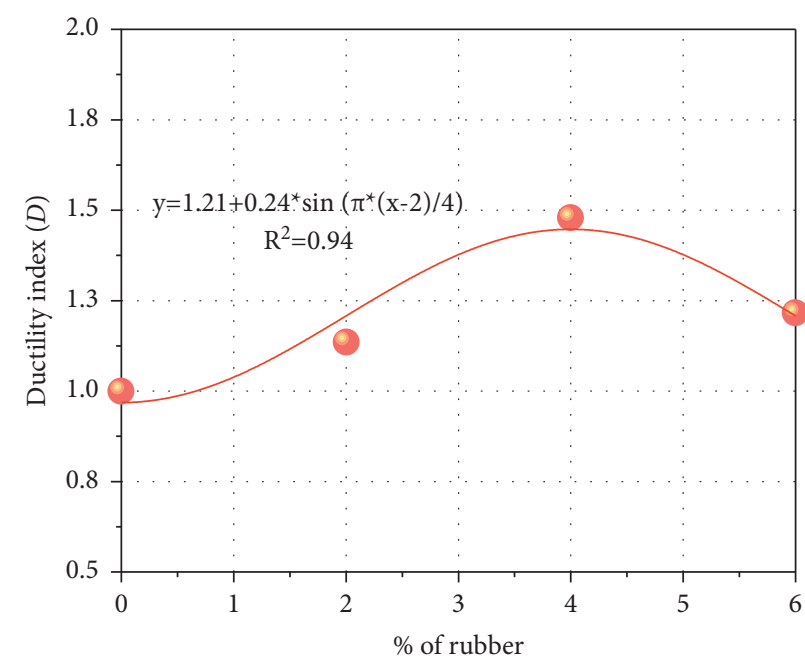

(a)

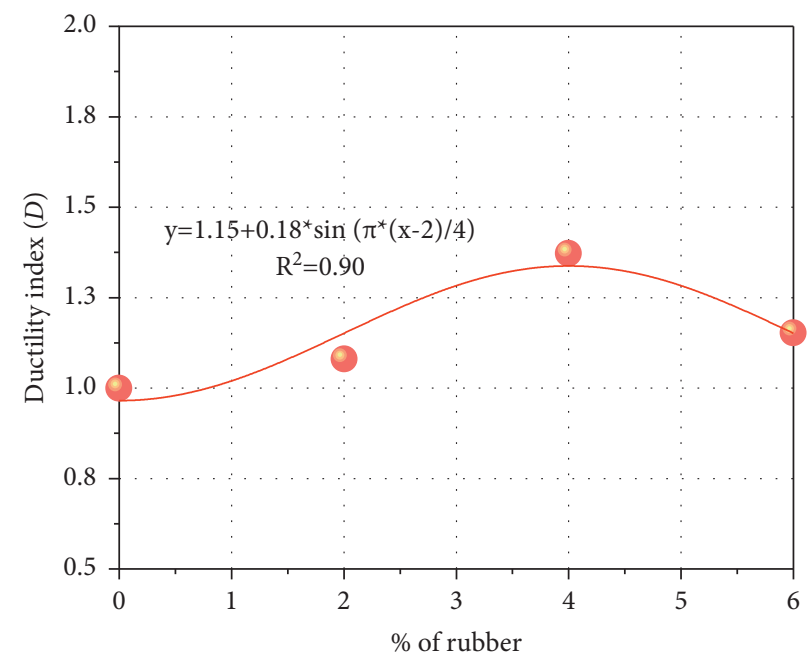

(b)

FIGURE 7: Relationship between the ductility index D and rubber content of cemented tailings for (a) $10 \%$ cement content samples and (b) $25 \%$ cement content samples.

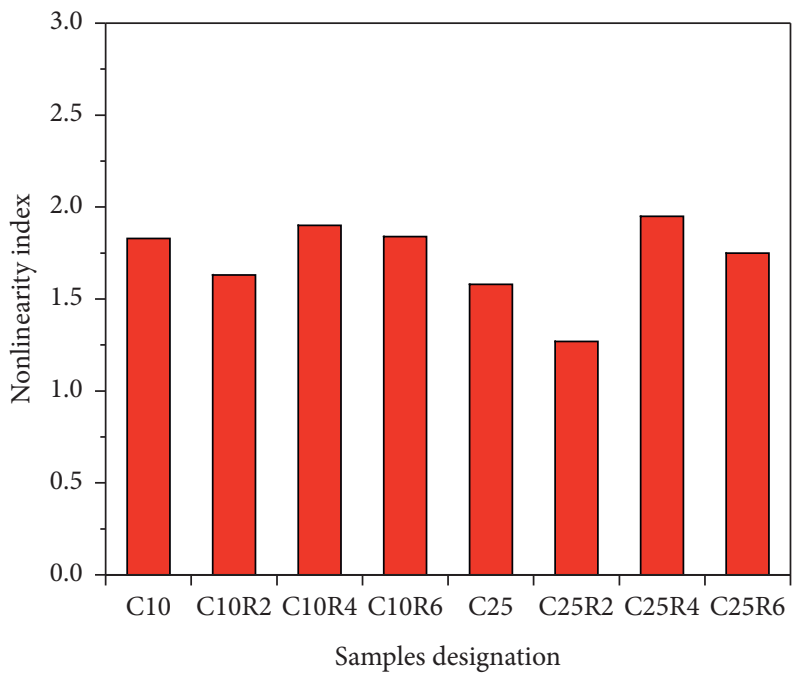

FIGURE 8: Nonlinearity index values of cemented tailings samples. 


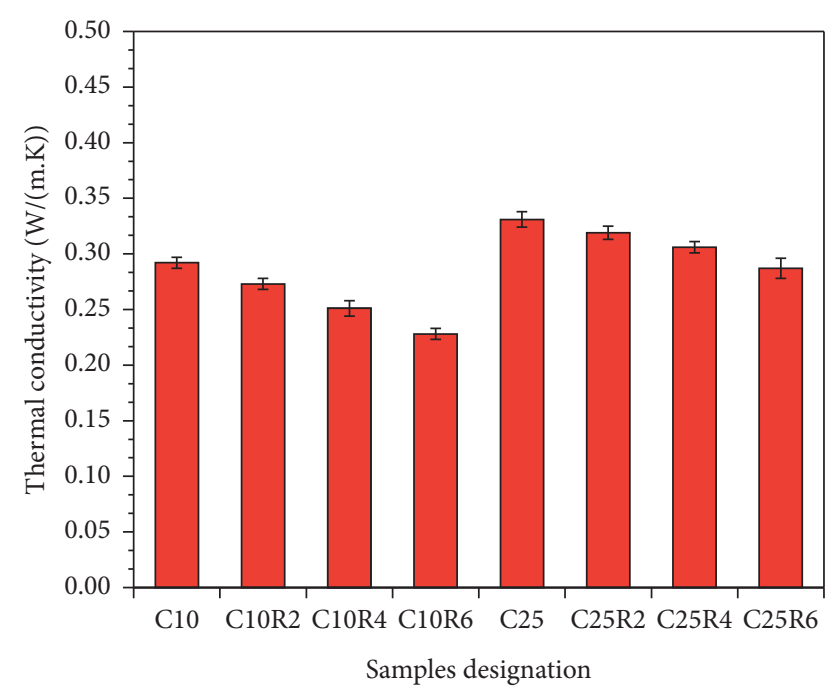

Figure 9: Values of thermal conductivity of cemented tailings samples.

conductivity values of samples C25, C25R2, C25R4, and C25R6 were $0.331 \mathrm{~W} /(\mathrm{m} \cdot \mathrm{K}), 0.319 \mathrm{~W} /(\mathrm{m} \cdot \mathrm{K}), 0.306 \mathrm{~W} /(\mathrm{m} \cdot \mathrm{K})$, and $0.287 \mathrm{~W} /(\mathrm{m} \cdot \mathrm{K})$, respectively. It can be seen that the thermal conductivity of cemented tailings decreased with increasing crumb rubber content. For instance, the thermal conductivity value of $10 \%$ cement content sample C10R6 was $21.9 \%$ lower than that of dried sample C10. Similarly, the thermal conductivity value of $25 \%$ cement content sample C25R6 was 13.2\% lower than that of undried sample C25. This may be due to the low thermal conductivity and density of the tire rubber. It can also be seen that the thermal conductivity of cemented tailings with higher cement content was higher than that of lower cement content cemented tailings. This result was consistent with the previous research on the self-compacting concrete [37]. It can be explained by the fact that large amounts of cement could produce more hydration products that could fill the pores and then increased the density and thermal conductivity [32]. The thermal conductivity values of cemented tailings ranged from $0.228 \mathrm{~W} /(\mathrm{m} \cdot \mathrm{K})$ to $0.331 \mathrm{~W} /(\mathrm{m} \cdot \mathrm{K})$, which was much lower than that of hardened cement $(0.9 \mathrm{~W} /(\mathrm{m} \cdot \mathrm{K}))$ and concrete $(1.5 \mathrm{~W} /(\mathrm{m} \cdot \mathrm{K}))$. Therefore, the cemented tailing was a good thermal insulation material. And increasing the rubber content can further increase the thermal insulation capacity of the cemented tailings. This indicated that the cemented tailings containing crumb rubber had a great potential to be used as a thermal insulation sandwich material in a structure or to improve the working environment when used as a backfill floor.

\section{Conclusions}

On the basis of the achieved findings, following conclusions could be drawn:

(1) The stress-strain behavior of cemented tailings was affected by the inclusion of crumb rubber. There were more pronounced pore compaction stages and plastic stages in the stress-strain curves of higher rubber content cemented tailings.

(2) The unconfined compressive strength of cemented tailings decreased as the crumb rubber content increased. It is important to ensure that the cemented tailings with crumb rubber have an acceptable strength by controlling the crumb rubber content and increasing the cement content appropriately.

(3) The inclusion of crumb rubber improved the ductility of cemented tailings. Larger failure strain and higher nonlinearity index were achieved in the cemented tailings containing crumb rubber. The addition of $4 \%$ crumb rubber provided the greatest improvement in ductility of cement tailings. It showed the great potential of this material when used as a pressure-bearing material under large deformations.

(4) The thermal conductivity values of cemented tailings materials were much lower than the hardened cement and concrete, which indicated that the cemented tailing is a good thermal insulation material. The increase of the rubber content could further increase the thermal insulation capacity of the cemented tailings. This revealed that the cemented tailings containing crumb rubber had a great potential to be used as an insulating sandwich material in a structure or to improve the working environment when used as a backfill floor.

(5) The low stiffness and dimpled surface of the crumb rubber were responsible for the reduced UCS and thermal conductivity of the cemented tailings. However, they also improved the ductility and thermal insulation of the cemented tailings.

\section{Data Availability}

The data used to support the findings of this study are available from the corresponding author upon request.

\section{Conflicts of Interest}

The authors declare that they have no conflicts of interest.

\section{Acknowledgments}

The authors would like to thank the financial support from the Natural Science Foundation of Shandong (ZR2021QE202), the State Key Laboratory of Coal Resources and Safe Mining (SKLCRSM19KF015), the Key Laboratory of Mine Disaster Prevention and Control (MDPC201915), and the Key Laboratory of Safety and High-Efficiency Coal Mining (JYBSYS2018204).

\section{References}

[1] W. Sun, H. Wang, and K. Hou, "Control of waste rock-tailings paste backfill for active mining subsidence areas," Journal of Cleaner Production, vol. 171, pp. 567-579, 2018. 
[2] Z. Zhang, Z. Zhang, S. Yin, and L. Yu, "Utilization of iron tailings sand as an environmentally friendly alternative to natural river sand in high-strength concrete: shrinkage characterization and mitigation strategies," Materials, vol. 13, no. $24,2020$.

[3] G. Wang, B. Hu, S. Tian, M. Ai, W. Liu, and X. Kong, "Seepage field characteristic and stability analysis of tailings dam under action of chemical solution," Scientific Reports, vol. 11, no. 1, 2021.

[4] N. Hu, C. M. Cheng, X. F. Wen, Y. Chen, and H. L. Hu, "Comparison study of scrap tires management between China and the USA," Advanced Materials Research, vol. 878, pp. 90-98, 2014.

[5] J. S. Yadav and S. K. Tiwari, "The impact of end-of-life tires on the mechanical properties of fine-grained soil: a Review," Environment, Development and Sustainability, vol. 21, no. 2, pp. 485-568, 2017.

[6] Q. Li, F. Li, A. Meng, Z. Tan, and Y. Zhang, "Thermolysis of scrap tire and rubber in sub/super-critical water," Waste Management, vol. 71, pp. 311-319, 2018.

[7] A. P. Gursel and C. Ostertag, "Life-cycle assessment of high-strength concrete mixtures with copper slag as sand replacement," Advances in Civil Engineering, vol. 2019, Article ID 6815348, 13 pages, 2019.

[8] S. Zhao, J. Fan, and W. Sun, "Utilization of iron ore tailings as fine aggregate in ultra-high performance concrete," Construction and Building Materials, vol. 50, pp. 540-548, 2014.

[9] W. Y. Liu, X. L. Xu, and Y. Y. An, "Study on the sprayed concrete with iron tailings," Advanced Materials Research, vol. 347-353, pp. 1939-1943, 2011

[10] A. Kesimal, E. Yilmaz, B. Ercikdi, I. Alp, and H. Deveci, "Effect of properties of tailings and binder on the short-and longterm strength and stability of cemented paste backfill," $M a$ terials Letters, vol. 59, no. 28, pp. 3703-3709, 2005.

[11] N. Zhou, C. Doung, S. Ouyang, and X. Deng, "Feasibility study and performance optimization of sand-based cemented paste backfill materials," Journal of Cleaner Production, vol. 259, no. 10, 2020.

[12] C. Qi, Q. Chen, A. Fourie, and Q. Zhang, “An intelligent modelling framework for mechanical properties of cemented paste backfill," Minerals Engineering, vol. 123, pp. 16-27, 2018.

[13] M. Sheshpari, "A review of underground mine backfilling methods with emphasis on cemented paste backfill," Electronic Journal of Geotechnical Engineering, vol. 20, pp. 5183-5208, 2015.

[14] M. Fall, J. C. Célestin, M. Pokharel, and M. Touré, “A contribution to understanding the effects of curing temperature on the mechanical properties of mine cemented tailings backfill," Engineering Geology, vol. 114, no. 3-4, pp. 397-413, 2010.

[15] S. Cao, E. Yilmaz, and W. Song, "Fiber type effect on strength, toughness and microstructure of early age cemented tailings backfill," Construction and Building Materials, vol. 223, pp. 44-54, 2019.

[16] Y. Wang, Z. Yu, and H. Wang, "Experimental investigation on some performance of rubber fiber modified cemented paste backfill," Construction and Building Materials, vol. 271, 2021.

[17] L. Guo, W. Li, X. Yang, and W. Xu, "Sodium silicate gel effect on cemented tailing backfill that contains lead-zinc smelting slag at early ages," Advances in Materials Science and Engineering, vol. 2018, Article ID 8502057, 6 pages, 2018.

[18] X. Chen, X. Shi, J. Zhou, Q. Chen, E. Li, and X. Du, "Compressive behavior and microstructural properties of tailings polypropylene fibre-reinforced cemented paste backfill," Construction and Building Materials, vol. 190, pp. 211-221, 2018.

[19] L. Festugato, A. Fourie, and N. C. Consoli, "Cyclic shear response of fibre-reinforced cemented paste backfill," Géotechnique Letters, vol. 3, no. 1, pp. 5-12, 2013.

[20] B. Koohestani, A. Koubaa, T. Belem, B. Bussière, and H. Bouzahzah, "Experimental investigation of mechanical and microstructural properties of cemented paste backfill containing maple-wood filler," Construction and Building $\mathrm{Ma}$ terials, vol. 121, pp. 222-228, 2016.

[21] F. C. Wang and W. Song, "Effects of crumb rubber on compressive strength of cement-treated soil," Archives Of Civil Engineering, vol. 61, no. 4, 2015.

[22] M. A. Aiello and F. Leuzzi, "Waste tyre rubberized concrete: properties at fresh and hardened state," Waste Management, vol. 30 , no. 8-9, pp. 1696-1704, 2010.

[23] N. N. Eldin and A. B. Senouci, "Rubber-tire particles as concrete aggregate," Journal of Materials in Civil Engineering, vol. 5, no. 4, pp. 478-496, 1993.

[24] A. O. Atahan and A. Ö. Yücel, "Crumb rubber in concrete: static and dynamic evaluation," Construction and Building Materials, vol. 36, pp. 617-622, 2012.

[25] L. Cui and M. Fall, "Mechanical and thermal properties of cemented tailings materials at early ages: influence of initial temperature, curing stress and drainage conditions," Construction and Building Materials, vol. 125, pp. 553-563, 2016.

[26] X. W. Yi, G. W. Ma, and A. Fourie, "Compressive behaviour of fibre-reinforced cemented paste backfill," Geotextiles and Geomembranes, vol. 43, no. 3, pp. 207-215, 2015.

[27] J. Zheng, L. Guo, X. Sun, W. Li, and Q. Jia, "Study on the strength development of cemented backfill body from leadzinc mine tailings with sulphide," Advances in Materials Science and Engineering, vol. 2018, Article ID 7278014, 8 pages, 2018.

[28] American Society of Testing Materials, Standard Test Method for Compressive Strength of Cylindrical concrete Specimens, ASTM International, West Conshohocken, 2002.

[29] American Society of Testing Materials, Standard Test Method for Determination of Thermal Conductivity of Soil and Soft Rock by Thermal Needle Probe ProcedureASTM International, West Conshohocken, 2014.

[30] J. T. Huang and D. W. Airey, "Properties of artificially cemented carbonate sand," Journal of Geotechnical and Geoenvironmental Engineering, vol. 124, no. 6, pp. 492-499, 1998.

[31] Y. H. Wang and S. C. Leung, "A particulate-scale investigation of cemented sand behavior," Canadian Geotechnical Journal, vol. 45, no. 1, pp. 29-44, 2008.

[32] M. Fall, T. Belem, S. Samb, and M. Benzaazoua, "Experimental characterization of the stress-strain behaviour of cemented paste backfill in compression," Journal of Materials Science, vol. 42, no. 11, pp. 3914-3922, 2007.

[33] B. W. Jo, G. H. Tae, and B. Y. Kwon, "Ductility evaluation of prestressed concrete beams with CFRP tendons," Journal of Reinforced Plastics and Composites, vol. 23, no. 8, pp. 843-859, 2016.

[34] M. Bekhiti, H. Trouzine, and M. Rabehi, "Influence of waste tire rubber fibers on swelling behavior, unconfined compressive strength and ductility of cement stabilized bentonite clay soil," Construction and Building Materials, vol. 208, pp. 304-313, 2019.

[35] A. R. Khaloo, M. Dehestani, and P. Rahmatabadi, "Mechanical properties of concrete containing a high volume of 
tire-rubber particles," Waste Management, vol. 28, no. 12, pp. 2472-2482, 2008.

[36] J. Zhang, Q. Zhang, A. J. S. Spearing, X. Miao, S. Guo, and Q. Sun, "Green coal mining technique integrating miningdressing-gas draining-backfilling-mining," International Journal of Mining Science and Technology, vol. 27, no. 1, pp. 17-27, 2017.

[37] M. Fenollera, J. Míguez, I. Goicoechea, and J. Lorenzo, "Experimental study on thermal conductivity of self-compacting concrete with recycled aggregate," Materials, vol. 8, no. 7, pp. 4457-4478, 2015. 